\title{
Controlling Gradient Domain Morphology in Blends of Poly(2-ethylhexyl acrylate-co-acrylic acid-co-vinyl acetate)/ Poly(vinylidene fluoride-co-hexafluoroacetone) by Adding Micrograin Silica
}

\author{
Yoshihisa Kano, Saburo AkiYama, ${ }^{\dagger}$ Hironari Sano, ${ }^{*}$ \\ and Hiroshi YUI** \\ Department of Chemical Science \& Technology, Faculty of Technology, Tokyo University of Agriculture and Technology, \\ Koganei-shi, Tokyo 184, Japan \\ * Mitsubishi Kagaku Co., Ltd., Yokkaichi-shi, Mie 510, Japan \\ ** AMCO Enterprises Incorporated, Shibuya-ku, Tokyo 150, Japan
}

(Received August 22, 1996)

\begin{abstract}
The gradient structure was observed for the sectional layer of the poly(2-ethylhexyl acrylate-co-acrylic acid-co-vinyl acetate); P(2EHA-AA-VAc)/poly(vinylidene fluoride-co-hexafluoro acetone); P(VDF-HFA) (30/70) blend thin film using SEM. The elipsoidal domain corresponded to P(2EHA-AA-VAc) particle was observed and its size increased from surface to bottom. In the bottom side, P(2EHA-AA-VAc) layer having $\sim 10 \mu \mathrm{m}$ thickness was formed. The characteristic gradient domain morphology was reduced by adding the micrograin silica into P(2EHA-AA-VAc)/P(VDF-HFA) (30/70) blend. Finally, pressure sensitive adhesive; PSA properties $\left(180^{\circ}\right.$ peel adhesion and probe tack) were evaluated in these blends on account of confirming the effect of the micrograin silica on the gradient structure.

KEY WORDS Blends / Gradient Structure / Micrograin Silica / Pressure Sensitive Adhesive / Scanning Electron Microscopy /
\end{abstract}

Recently, the design of the gradient structure has been carried out for binary polymer blends. In the gradient structure, the concentration of one component changes from surface to bottom. The gradient structure made of metal and ceramics is already noted as an air-space material. ${ }^{1}$ Agari et al. ${ }^{2}$ prepared the gradient structure in the blends of poly(vinyl chloride): PVC with poly(methyl methacrylate): PMMA by a dissolution and diffusion method. They classified gradient blend films prepared by various conditions, such as various kinds of solvent, casting temperature, molecular weights of PVC, and amounts of PMMA solution into five types. Finally, the physical properties (tensile strength, $\tan \delta$ ) of the PVC/PMMA gradient blend were compared with those of a homogeneously miscible blends, PVC, PMMA, and a PVC-PMMA laminate film. Okazaki and coworkers ${ }^{3}$ noted that the higher order structure of polyurethane elastomer could be changed by thermal hysteresis. They prepared the gradient structure by controlling temperature between surface and bottom of the mold.

On the other hand, in the blends of P(2EHA-AA-VAc) and P(VDF-HFA) $\mathrm{we}^{4-10}$ prepared the gradient structure by coating from THF solution. Since P(VDF-HFA) component enriched on surface and P(2EHA-AA-VAc) segregated at bottom, the tack value of bottom side was remarkably larger than that of surface side. We presumed that the characteristic gradient structure was formed by miscibility, difference of surface tension between component, rate of solvent evaporation and convection in solution. Finally, we expected that these blends can be utilized as non-backing pressure sensitive adhesive. In the previous study, ${ }^{7,10}$ the sectional layer of P(2EHA-AA-VAc)/P(VDF-HFA) blends was observed using SEM and TEM. In the P(2EHA-AA-

† To whom correspondence should be addressed.
VAc)/P(VDF-HFA) (50/50), (30/70) blends, the elipsoidal domain of P(2EHA-AA-VAc) was observed and its size increased from surface to bottom. Particularly, since P(2EHA-AA-VAc) layer of about $0.5 \sim 3 \mu \mathrm{m}$ thickness was observed in the bottom side, the difference of tackiness value between surface and bottom was very large.

Incidentally, controlling the dispersive structure is very important for immiscible blends such as modulated structure ${ }^{11}$ and salami structure. ${ }^{12}$ It is well known that the effect of adding compatibilizer on morphology is remarkably for immiscible polymer blends. For instance, Kim and Akiyama et al. ${ }^{13}$ examined the morphology of polycarbonate/nylon alloys using poly(allyl-co-maleic anhydride) as compatibilizer. They found that the compatibility between polycarbonate and nylon could be advanced by the compatibilizer. Therefore, it could be very interesting to introduce third component into the gradient structure formed in binary polymer blends.

In this study, we selected the micrograin silica as the third component and investigated the effect of adding the micrograin silica on the gradient structure formed for the P(2EHA-AA-VAc)/P(VDF-HFA) blends. Since the ratio of surface area and mass for the micrograin silica is very large, the morphology of the gradient structure formed in the P(2EHA-AA-VAc)/P(VDFHFA) blends may be modified by adding the micrograin silica. This effect was evaluated through SEM observation of sectional layer and pressure sensitive adhesive; PSA properties $\left(180^{\circ}\right.$ peel adhesion and probe tack $)$.

\section{EXPERIMENTAL}

The P(2EHA-AA-VAc) and P(VDF-HFA) were synthesized by Mitsubishi Kagaku Co., Ltd. and Central Glass Co., Ltd., respectively. The compositions and molecular weights of copolymers are represented in Table 
Table I. Components and molecular weights ${ }^{\mathrm{a}}$ of copolymers

\begin{tabular}{ll}
\hline P(2EHA-AA-VAc) & 2-Ethylhexyl acrylate/acrylic acid/vinyl \\
& acetate $=85 / 5 / 10(\mathrm{~mol} \%)$ \\
& $\bar{M}_{n}=45500, \bar{M}_{w}=372000$ \\
P(VDF-HFA) & Vinylidene fluoride $/$ hexafluoro acetone \\
& $=92 / 8(\mathrm{~mol} \%)$ \\
& $\bar{M}_{n}=52000, \bar{M}_{w}=130000$
\end{tabular}

${ }^{a}$ Molecular weight equivalent to that of polystyrene by GPC.

Table II. Characteristics of micrograin silica

\begin{tabular}{|c|c|c|}
\hline \multirow{2}{*}{ Sample } & Particle size & Specific surface area \\
\hline & $\mathrm{nm}$ & $\mathrm{m}^{2} \mathrm{~g}^{-1}$ \\
\hline R972 & 15 & 170 \\
\hline MOX170 & 15 & 170 \\
\hline
\end{tabular}

I. Two types of the micrograin silica (R972 and MOX170) supplied by Nippon AEROSIL Co., Ltd. were utilized as the third component. The MOX170 and R972 contain $\mathrm{Si}-\mathrm{OH}$ and $\mathrm{Si}-\mathrm{OCH}_{3}$, respectively. Table II shows the characteristics of the micrograin silica.

The films of P(2EHA-AA-VAc)/P(VDF-HFA)/micrograin silica blends were prepared onto PET film or the release liner using the hand coating bar from 20 (wt \%) THF solution. The release liner is the poly(dimethyl siloxane) coated on liner. ${ }^{7}$

After coating films were permitted to stand at room temperature for at least $24 \mathrm{~h}$, they were further allowed to dry in a vacuum for 7 days at $40^{\circ} \mathrm{C}$. The specimens were $20 \sim 23 \mu \mathrm{m}$ thick. The surface of blends was covered by release liner.

The surface and bottom of the P(2EHA-AA-VAc)/ $\mathrm{P}(\mathrm{VDF}-\mathrm{HFA}) /$ micrograin silica blends were observed using Hitachi Ltd. scanning electron microscopy (SEM) type S-2100. The surface and bottom of blends were treated by vacuum evaporation with $\mathrm{Au}$ using an Eiko Engineering Co., Ltd. IB-3 ion coater.

The sectional layer of P(2EHA-AA-VAc)/P(VDFHFA)/micrograin silica blends was observed using Hitachi Ltd. SEM type S-800 at room temperature. The films of blends were embeded in epoxy resin (Ouken Co., Ltd. EPON 812) at $30 \sim 40^{\circ} \mathrm{C}$ for $24 \mathrm{~h}$. Then, the embeded blends were cut into about $0.1 \mu \mathrm{m}$ sections at $-120^{\circ} \mathrm{C}$ with an ultra-microtome Reihert ULTRACUT-N (knife: Diatome) and stained with ruthenium tetraoxide $\left(\mathrm{RuO}_{4}\right)$.

The glass transition temperature $\left(T_{\mathrm{g}}\right)$ values of $\mathrm{P}$ (2EHA-AA-VAc)/P(VDF-HFA)/micrograin silica blends were determined using a 910 DSC with Du Pont 990 system at a heating rate of $10^{\circ} \mathrm{Cmin}^{-1}$.

The $180^{\circ}$ peel adhesion to stainless steel of the bottom side of blends was carried out with a Orientec Co., Ltd. TENSIRON/RTC-1250. The tack of surface and bottom was performed by means of the probe tack. The probe was made of stainless steel. The probe tack was measured using Nichiban Co., Ltd. probe tack tester. The backing was PET film of $50 \mu \mathrm{m}$ thick. These measurements were performed at $23^{\circ} \mathrm{C}$.

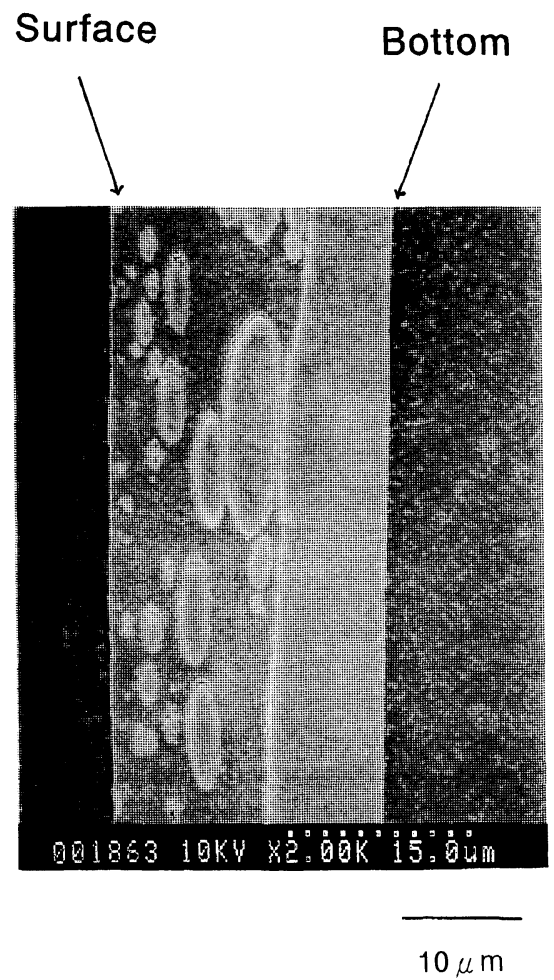

Figure 1. SEM photograph of sectional layer for P(2EHA-AAVAc)/P(VDF-HFA) (30/70) blend.

\section{RESULTS AND DISCUSSION}

The SEM photograph of sectional layer for $(30 / 70)$ blend is shown in Figure 1. The elipsoidal domain corresponded to $\mathrm{P}$ (2EHA-AA-VAc) particle is observed and its size increases from surface to bottom. The P(2EHA-AA-VAc) layer having $\sim 10 \mu \mathrm{m}$ thickness is observed in the bottom side. In our previous paper, ${ }^{7,10}$ the P(2EHA-AA-VAc) layer of about $0.5 \sim 3 \mu \mathrm{m}$ thickness was observed in the bottom side of $\mathrm{P}(2 \mathrm{EHA}-\mathrm{AA}$ VAc)/P(VDF-HFA) $(50 / 50),(30 / 70)$ blends. However, the $\mathrm{P}(2 \mathrm{EHA}-\mathrm{AA}-\mathrm{VAc})$ layer of $10 \mu \mathrm{m}$ thickness is observed in this study. In the previous study, ${ }^{7}$ the dry condition of the prepared blend film was at $90^{\circ} \mathrm{C}$ for $1 \mathrm{~min}$. The previous dry condition was regarded as the more fast rate of solvent evaporation. On the other hand, the dry condition on this study (at room temperature for at least $24 \mathrm{~h}$ ) was regarded as the slower rate of solvent evaporation. Thus, it is thought that this discrepancy of thickness of P(2EHA-AA-VAc) layer is attributed to the rate of solvent evaporation. In the $\mathrm{P}(2 \mathrm{EHA}-\mathrm{AA}-\mathrm{VAc})$ / P(VDF-HFA) (30/70) blend, the distribution of domain area \% corresponded to $\mathrm{P}(2 \mathrm{EHA}-\mathrm{AA}-\mathrm{VAc})$ particle against depth direction is shown in Figure 2. The normalized domain area $\%$ was defined as the ratio of $\mathrm{P}$ (2EHA-AA-VAc) domain area in the respective depth regions to total $\mathrm{P}(2 \mathrm{EHA}-\mathrm{AA}-\mathrm{VAc})$ domain area $=100 \%$ observed in the sectional layer. The distribution was obtained by dividing into three parts. The area $\%$ of P(2EHA-AA-VAc) particle markedly increases from surface to bottom. The area ratio of $\mathrm{P}(2 \mathrm{EHA}-\mathrm{AA}-\mathrm{VAc})$ particles in the surface region $(0 \sim 7 \mu \mathrm{m})$ and central region $(7 \sim 14 \mu \mathrm{m})$ are $10 \%$ and $20 \%$, respectively. On the other hand, the area ratio in the bottom region $(14 \sim 21 \mu \mathrm{m})$ are $70 \%$. 
$\mathrm{P}(2 \mathrm{EHA}-\mathrm{AA}-\mathrm{VAc}) / \mathrm{P}(\mathrm{VDF}-\mathrm{HFA})=\mathbf{3 0 / 7 0}$

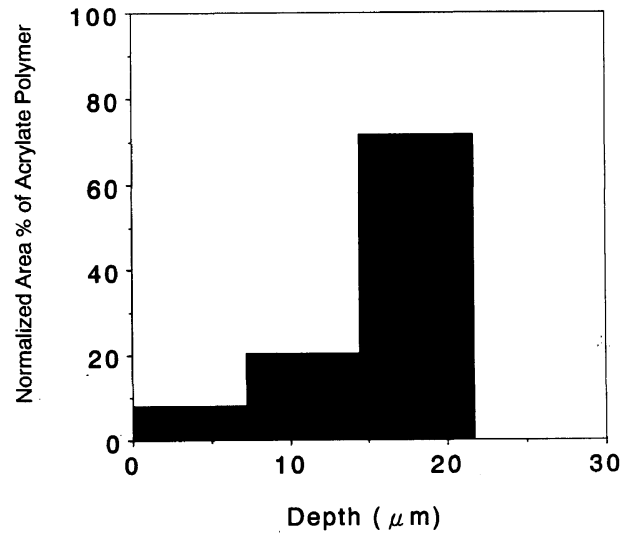

Figure 2. Relationship between normalized area \% of acrylate polymer and depth for P(2EHA-AA-VAc)/P(VDF-HFA) $(30 / 70)$ blend.

Table III. Compositions of P(2EHA-AA-VAc)/P(VDF-HFA)/ micrograin silica blends

\begin{tabular}{|c|c|c|c|}
\hline \multicolumn{2}{|c|}{ Silica content } & \multirow{2}{*}{$\frac{\mathrm{P}(2 \mathrm{EHA}-\mathrm{AA}-\mathrm{VAc})}{w \mathrm{t} \%}$} & \multirow{2}{*}{$\frac{\mathrm{P}(\text { VDF-HFA })}{\mathrm{wt} \%}$} \\
\hline$w t \%$ & & & \\
\hline & 0 & 30 & 70 \\
\hline R972 & 0.5 & 29.5 & 70 \\
\hline R972 & 2.0 & 28 & 70 \\
\hline MOX170 & 0.5 & 29.5 & 70 \\
\hline MOX170 & 2.0 & 28 & 70 \\
\hline
\end{tabular}

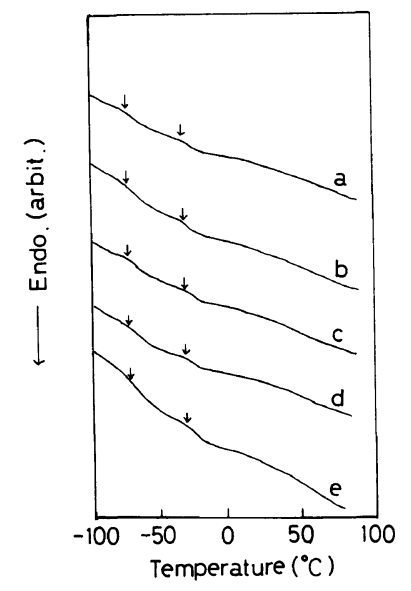

Figure 3. DSC thermograms of $\mathbf{P}(2 \mathrm{EHA}-\mathrm{AA}-\mathrm{VAc}) / \mathrm{P}(\mathrm{VDF}-\mathrm{HFA}) /$ micrograin silica blends. Silica content (wt\%): a) 0; b) 0.5 (R972); c) 2 (R972); d) 0.5 (MOX170); e) 2 (MOX170).

Next, we examined the effect of adding the micrograin silica on the gradient structure formed for the P(2EHAAA-VAc)/P(VDF-HFA) (30/70) blend. Since the formation of gradient structure for acrylate polymer/fluorocopolymer blends is influenced by miscibility between components, ${ }^{14,15}$ the miscibility of P(2EHA-AA-VAc)/ $\mathrm{P}(\mathrm{VDF}-\mathrm{HFA}) /$ the micrograin silica blends was evaluated by DSC. The compositions of P(2EHA-AA-VAc)/ $\mathrm{P}(\mathrm{VDF}-\mathrm{HFA}) /$ micrograin silica blends are shown in Table III. Figure 3 shows DSC thermograms of $\mathrm{P}$ (2EHA-AA-VAc)/P(VDF-HFA)/the micrograin silica blends. In all blends, the peaks corresponding to glass transition temperature $T_{\mathrm{g}}$ for P(2EHA-AA-VAc) and

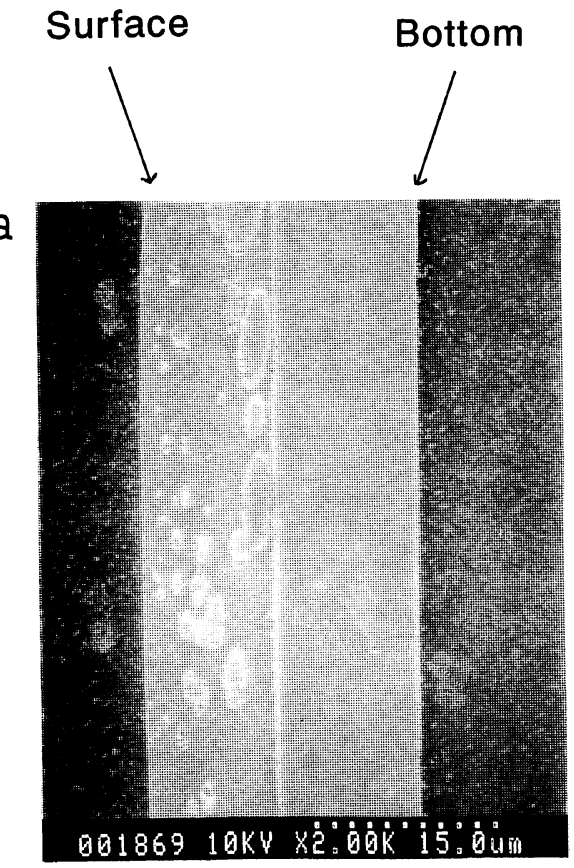

$10 \mu \mathrm{m}$

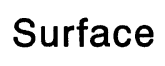

Bottom
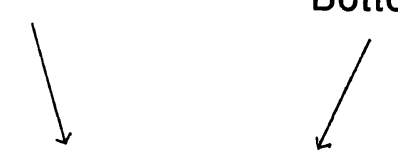

b

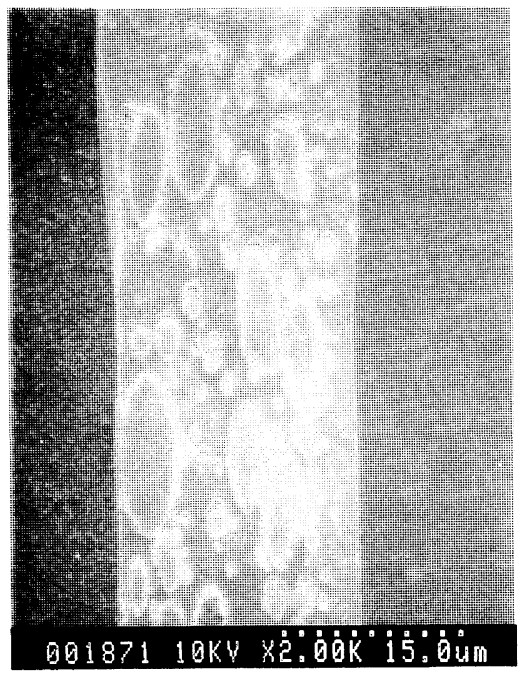

$10 \mu \mathrm{m}$

Figure 4. SEM photographs of sectional layer for P(2EHA-AAVAc)/P(VDF-HFA)/R972 blends. Silica content (wt\%): a) 0.5; b) 2.

$\mathrm{P}(\mathrm{VDF}-\mathrm{HFA})$ are observed around $-70^{\circ} \mathrm{C}$ and $-25^{\circ} \mathrm{C}$, respectively. Since the immiscibility in these blends are confirmed from the results of DSC thermograms, we judge that the miscibility between $\mathrm{P}(2 \mathrm{EHA}-\mathrm{AA}-\mathrm{VAc})$ and $\mathrm{P}$ (VDF-HFA) could not be improved by introducing the $2(w t \%)$ micrograin silica. Figure 4 shows SEM photographs of sectional layer for P(2EHA-AA-VAc)/ $\mathrm{P}(\mathrm{VDF}-\mathrm{HFA}) / \mathrm{R} 972$ blends. When 0.5 (wt\%) R972 is introduced into blend, the morphology of sectional layer scarcely change compared with that of P(2EHA-AA- 
VAc)/P(VDF-HFA) (30/70) blend. However, the sectional layer for P(2EHA-AA-VAc)/P(VDF-HFA)/R972 $(28 / 70 / 2)$ blend obviously differed in the morphology, i.e., the characteristic gradient domain morphology and $\mathrm{P}$ (2EHA-AA-VAc) layer were become remarkably smaller by adding 2 (wt \%) R972 into P(2EHA-AA-VAc)/ $\mathrm{P}$ (VDF-HFA) $(30 / 70)$ blend. Therefore, it is expected that the gradient structure formed in the P(2EHA-AAVAc)/P(VDF-HFA) (30/70) blend could be controlled by adding the micrograin silica (R972). In other words,
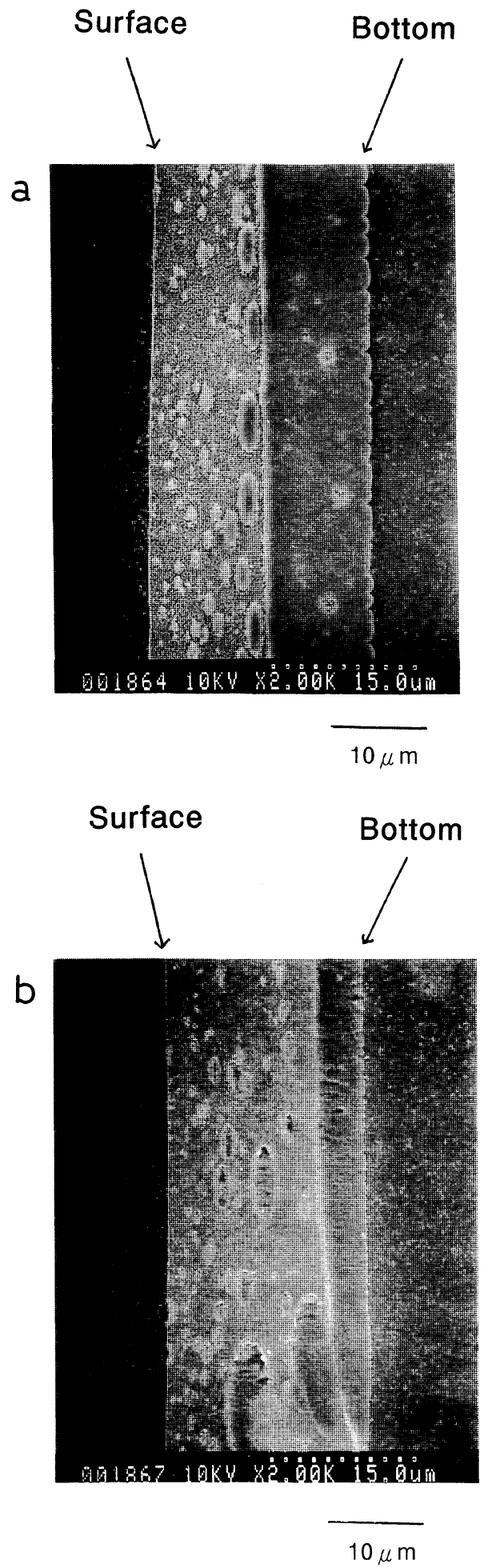

Figure 5. SEM photographs of sectional layer for P(2EHA-AAVAc)/P(VDF-HFA)/MOX170 blends. Silica content (wt \%): a) 0.5 (MOX170); b) 2 (MOX170).
R972 can act as disperse agent in the P(2EHA-AAVAc)/P(VDF-HFA) (30/70) blend. Figure 5 shows SEM photographs of sectional layer for $\mathrm{P}(2 \mathrm{EHA}-\mathrm{AA}-\mathrm{VAc}) /$ P(VDF-HFA)/MOX170 blends. The thickness of $\mathrm{P}(2 \mathrm{EHA}-\mathrm{AA}-\mathrm{VAc})$ layer slightly decreased with adding $2(\mathrm{wt} \%)$ MOX170. However, the effect of MOX170 is markedly weaker than that of R972. It is difficult to explain why the effect of R972 is superior to that of MOX170 on the controlling gradient structure and the difference of the inclination of gradient structure between adding 0.5 and $2(\mathrm{wt} \%)$ of micrograin silica. The difference of chemical structure between R972 (Si$\left.\mathrm{OCH}_{3}\right)$ and MOX170 (Si-OH) may affect to the controlling morphology of gradient structure. The relationships between normalized area $\%$ of $\mathrm{P}(2 \mathrm{EHA}-$ AA-VAc) particle and depth for $\mathrm{P}(2 \mathrm{EHA}-\mathrm{AA}-\mathrm{VAc}) /$ $\mathrm{P}(\mathrm{VDF}-\mathrm{HFA}) /$ micrograin silica blends are shown in Figure 6. Evidently, the relationship between normalized area $\%$ and depth of the blend with 2 (wt \%) R972 differs from those of other blends. The elipsoidal domain corresponded to $\mathrm{P}(2 \mathrm{EHA}-\mathrm{AA}-\mathrm{VAc})$ particle in the blend with 2 (wt\%) R972 homogeneously distributed against depth direction. Thus, the PSA properties of the blend containing 2 (wt\%) R972 should significantly differ from those of other blends. That is to say, it is possible that the difference of tack value between surface and bottom is very small.

Probe tack values of $\mathrm{P}(2 \mathrm{EHA}-\mathrm{AA}-\mathrm{VAc}) / \mathrm{P}(\mathrm{VDF}-$ HFA)/micrograin silica blends are summarized in Table IV. The probe tack value of surface side is remarkably smaller than that of bottom side for P(2EHA-AAVAc)/P(VDF-HFA) (30/70) blend because as shown in Figure 1, P(VDF-HFA) matrix phase and P(2EHA-AAVAc) layer is formed at surface side and bottom side, respectively. In the blends with 0.5 (wt\%) $\mathrm{R} 972$ and 0.5 $(\mathrm{wt} \%)$ MOX170, the differences of probe tack between surface and bottom are similar to that in the $(30 / 70)$ blend. These results is corresponded to the SEM photogaphs of sectional layer. The differences of probe tack value between surface and bottom for P(2EHA-AA$\mathrm{VAc}) / \mathrm{P}(\mathrm{VDF}-\mathrm{HFA}) /$ micrograin silica $(28 / 70 / 2)$ blends are smaller than those for blends containing 0.5 (wt $\%)$ micrograin silica. Particularly, the probe tack of the blend with 2 (wt \%) R972 is significant, since P(2EHA-AAVAc) layer was completely dispersed by the effect of R972. On the other hand, although the bottom side for P(2EHA-AA-VAc)/P(VDF-HFA)/MOX170 (28/70/2) blend was covered with $\mathrm{P}(2 \mathrm{EHA}-\mathrm{AA}-\mathrm{VAc})$ layer, the probe tack value of bottom also decreased in this blend. As shown in SEM photograph of Figure 5-b, P(2EHAAA-VAc) layer of $\sim 5 \mu \mathrm{m}$ thickness may influence the probe tack. As other reason, it is considered that the adding micrograin silica into $\mathrm{P}(2 \mathrm{EHA}-\mathrm{AA}-\mathrm{VAc}) /$ $\mathrm{P}(\mathrm{VDF}-\mathrm{HFA})$ blends may influence the probe tack value.

The $180^{\circ}$ peel strength of bottom side for $\mathrm{P}(2 \mathrm{EHA}$ AA-VAc)/P(VDF-HFA)/micrograin silica blends to stainless steel is represented in Table $\mathrm{V}$. The cohesive failure of blend layer was observed for all blends and its strength decreased with increasing micrograin silica. The decrease of peel strength may be influenced by the dispersing force of micrograin silica. The peel strength of P(2EHA-AA-VAc)/P(VDF-HFA)/R972 (28/70/2) blend is remarkably smaller than those of other blends. 
$\mathrm{P}$ (2日HA-AA-VAc)/ P(VDF-HFA)/ R972 $=29.5 / 70 / 0.5$

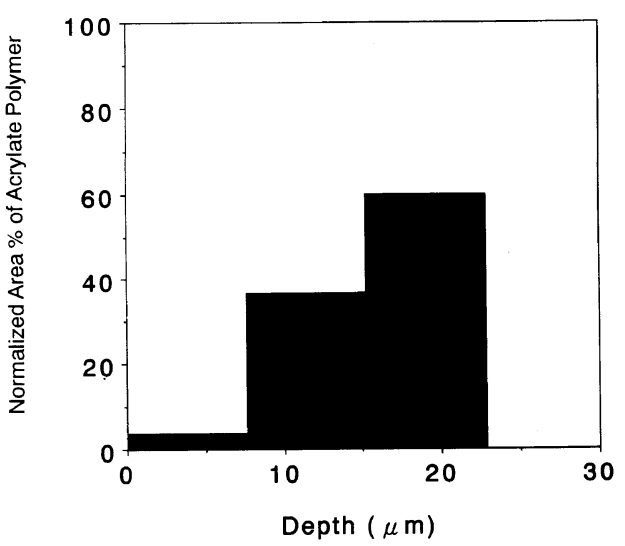

$\mathrm{P}$ (2EHA-AA-VAc)/P(VDF-HFA)/MOX170 $=29.5 / 70 / 0.5$

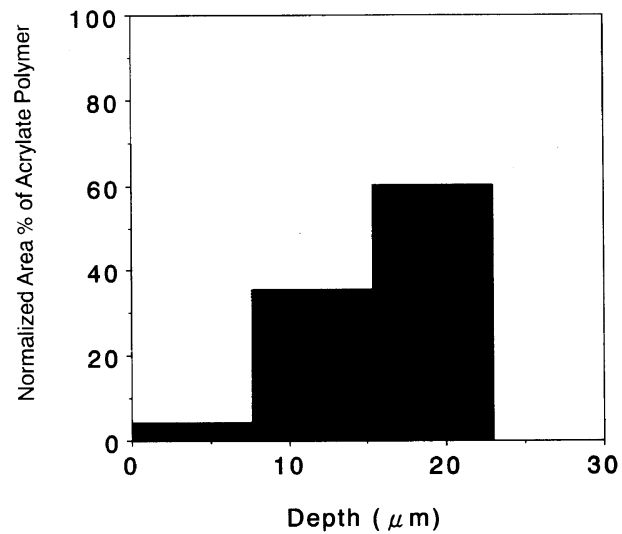

$\mathrm{P}$ (2日AA-AA-VAc)/ P(VDF-HFA)/ R972 $=28 / 70 / 2$

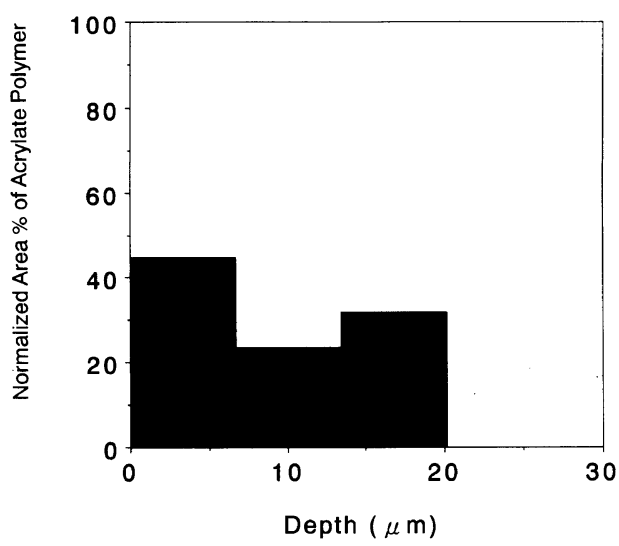

$\mathrm{P}$ (2EHA-AA-VAc)/P(VDF-HFA)/MOX170 $=28 / 70 / 2$

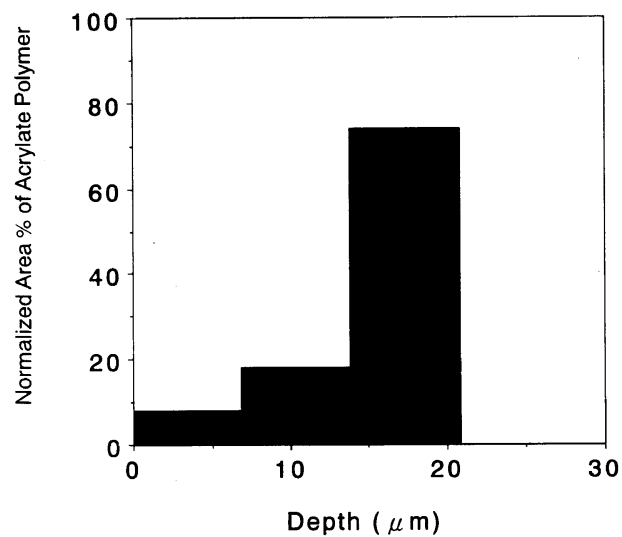

Figure 6. Relationship between normalized area $\%$ of acrylate polymer and depth for $\mathrm{P}(2 \mathrm{EHA}-\mathrm{AA}-\mathrm{VAc}) / \mathrm{P}(\mathrm{VDF}-\mathrm{HFA}) / \mathrm{micrograin}$ silica blends.

Table IV. Probe tack $(\mathrm{g} / 5 \mathrm{~mm} \phi)$ of P(2EHA-AA-VAc)/ $\mathrm{P}(\mathrm{VDF}-\mathrm{HFA}) / \mathrm{micrograin}$ silica blends

\begin{tabular}{clcr}
\hline $\begin{array}{c}\text { Silica content/ } \\
\text { wt } \%\end{array}$ & Surface & Bottom \\
\hline & 0 & 13 & 540 \\
R972 & 0.5 & 9 & 544 \\
R972 & 2.0 & 9 & 34 \\
MOX170 & 0.5 & 14 & 583 \\
MOX170 & 2.0 & 9 & 137 \\
\hline
\end{tabular}

In this blend, after P(2EHA-AA-VAc) layer for the blend containing 2 (wt $\%)$ R972 was disintegrated by the dispersing effect of R972, P(VDF-HFA) and P(2EHAAA-VAc) components became matrix and elipsoidal domain, respectively. We think that this formation of $\mathrm{P}(\mathrm{VDF}-\mathrm{HFA})$ matrix influences the reduction of peel strength because of non-tackiness P(VDF-HFA). From the results of SEM observation of sectional layer and PSA properties, it is clear that the introducing micrograin silica into $\mathrm{P}(2 \mathrm{EHA}-\mathrm{AA}-\mathrm{VAc}) / \mathrm{P}(\mathrm{VDF}-\mathrm{HFA}) \quad(30 / 70)$ blend exhibiting gradient structure is very effective to controll this characteristic morphology.

The effect of adding micrograin silica on surface and bottom topographies for P(2EHA-AA-VAc)/P(VDF-
Table V. Peel strength $(\mathrm{g} / 25 \mathrm{~mm})$ of P(2EHA-AA-VAc)/ $\mathrm{P}(\mathrm{VDF}-\mathrm{HFA}) /$ micrograin silica blends ${ }^{\mathrm{a}}$

\begin{tabular}{cll} 
Silica content/wt $\%$ & Peel strength $(\mathrm{g} / 25 \mathrm{~mm})$ \\
& 0 & $\mathrm{CF} / 1090$ \\
$\mathrm{R} 972$ & 0.5 & $\mathrm{CF} / 990$ \\
$\mathrm{R} 972$ & 2.0 & $\mathrm{CF} / 10$ \\
MOX170 & 0.5 & $\mathrm{CF} / 850$ \\
MOX170 & 2.0 & $\mathrm{CF} / 380$ \\
\hline
\end{tabular}

${ }^{\text {a }} \mathrm{CF}$, cohesive failure in adhesive layer.

HFA) (30/70) blend was also examined by SEM. The SEM photographs of surface and bottom for P(2EHAAA-VAc)/P(VDF-HFA)/R972 (28/70/2) blend are shown in Figure 7 . The morphology of the blend with R972 is dissimilar that of sectional layer as $(30 / 70)$ blend. The heterogeneous morphology is observed in surface of $(28 / 70 / 2)$ blend, whereas the wrinkled morphology is existed in bottom side. It is thought that the dispersing effect of R972 affects the surface and bottom morphologies. Since the number of wrinkled morphology for $(28 / 70 / 2)$ blend with R972 is remarkably less than that for (30/70) blend,we presume that the difference of PSA properties between (28/70/2) with R972 and (30/70) blends is also attributed to the discrepancy of surface 
A

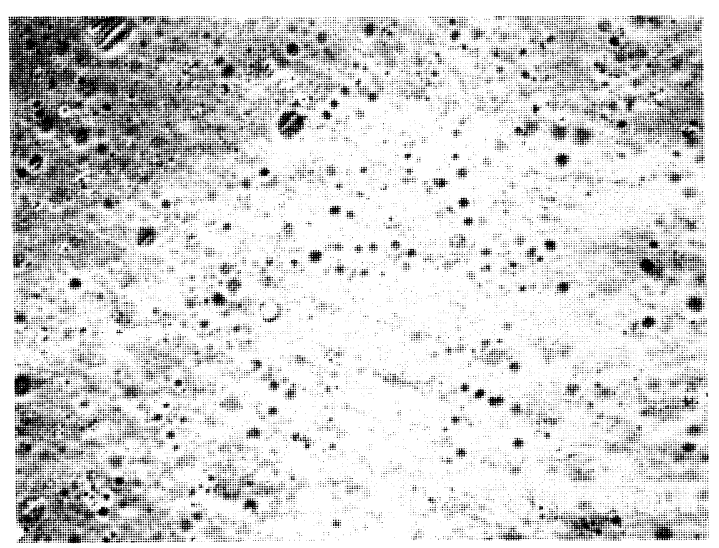

B

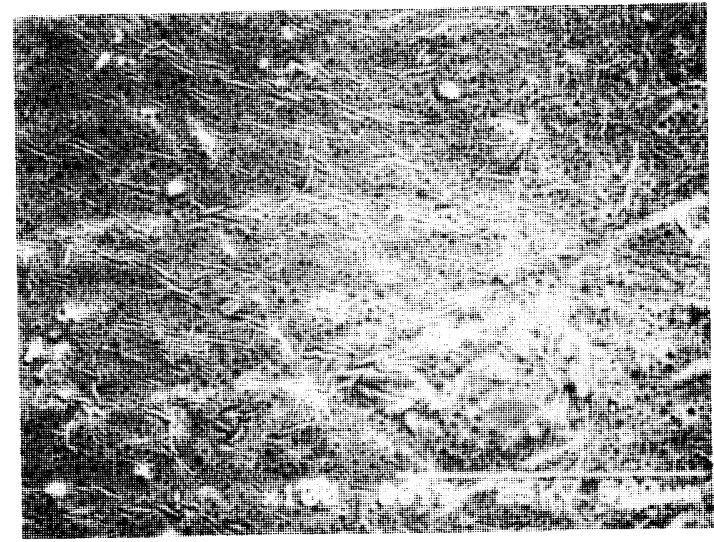

Figure 7. SEM photographs of $\mathrm{P}(2 \mathrm{EHA}-\mathrm{AA}-\mathrm{VAc}) / \mathrm{P}(\mathrm{VDF}-\mathrm{HFA}) /$ R972 $=28 / 70 / 2$ blend. A) surface side; B) bottom side

A

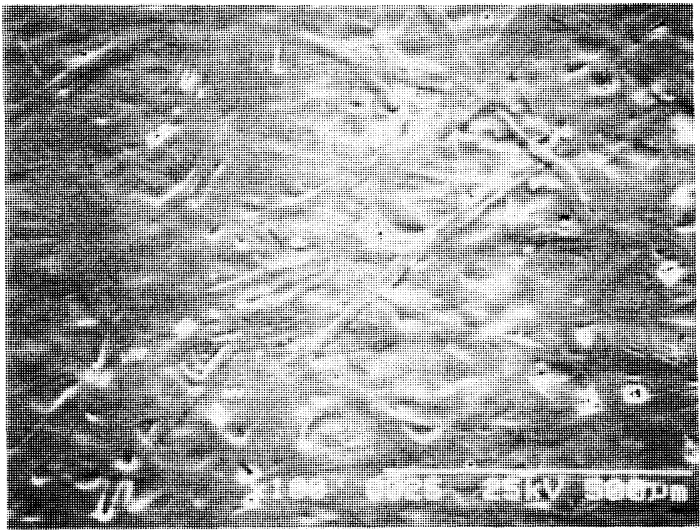

B

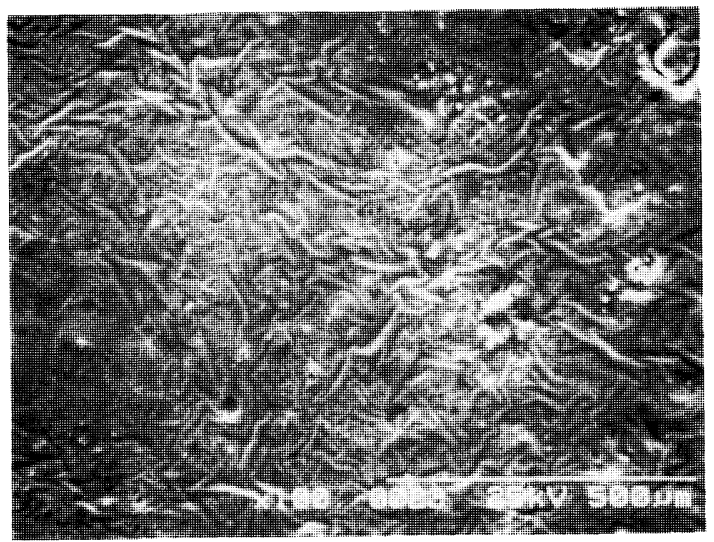

Figure 8. SEM photographs of $\mathrm{P}(2 \mathrm{EHA}-\mathrm{AA}-\mathrm{VAc}) / \mathrm{P}(\mathrm{VDF}-\mathrm{HFA}) /$ MOX $170=28 / 70 / 2$ blend. A) surface side; B) bottom side. and bottom morphologies. Figure 8 shows the SEM photographs of surface and bottom for P(2EHA-AAVAc)/P(VDF-HFA)/MOX170 $(28 / 70 / 2)$ blend. The surface morphology also differs from the bottom morphology for $(28 / 70 / 2)$ blend. In the bottom side, the number of wrinkled morphology for the blend containing $2(\mathrm{wt} \%)$ MOX170 is higher than that for the blend with 2 (wt \%) R972. Since the wrinkled morphology is corresponded to $\mathrm{P}(2 \mathrm{EHA}-\mathrm{AA}-\mathrm{VAc})$ component, it is thought that the difference of the number of wrinkled morphology observed at bottom side affects the difference of the values of probe tack and peel strength. Therefore, the effect of adding micrograin silica on surface and bottom morphologies was also confirmed by SEM analysis.

Finally, we modified the elipsoidal domain of P(2EHA-AA-VAc) component observed in the P(2EHAAA-VAc)/P(VDF-HFA) (30/70) blend. It is anticipated that the elipsoidal domain was formed at the process of solvent evaporation. Thus the elipsoidal domain morphology is formed due to non-equilibrium state. If the blend having elipsoidal domain was annealed at the temperature higher than melting temperature $\left(T_{\mathrm{m}}\right)$, the elipsoidal domain would become the spherical domain. The SEM photograph of sectional layer for annealed $\mathrm{P}(2 \mathrm{EHA}-\mathrm{AA}-\mathrm{VAc}) / \mathrm{P}$ (VDF-HFA) $(30 / 70)$ blend is shown in Figure 9. The specimen used in this experiment was quenched by liquid nitrogen after annealed at $160^{\circ} \mathrm{C}$ for 2 days. The P(2EHA-AA-VAc) layer is formed at the bottom side. However, the spherical domain of $\mathrm{P}(2 \mathrm{EHA}$ AA-VAc) component is observed in the P(VDF-HFA) matrix at surface side. Therefore, the domain morphology corresponded to P(2EHA-AA-VAc) found to change by annealing.

By the way, since the glass transition temperatures $T_{\mathrm{g}}$ of P(2EHA-AA-VAc) and P(VDF-HFA) are much lower than the room temperature, the domain morphology of the blends may be changed with elapsed time at room

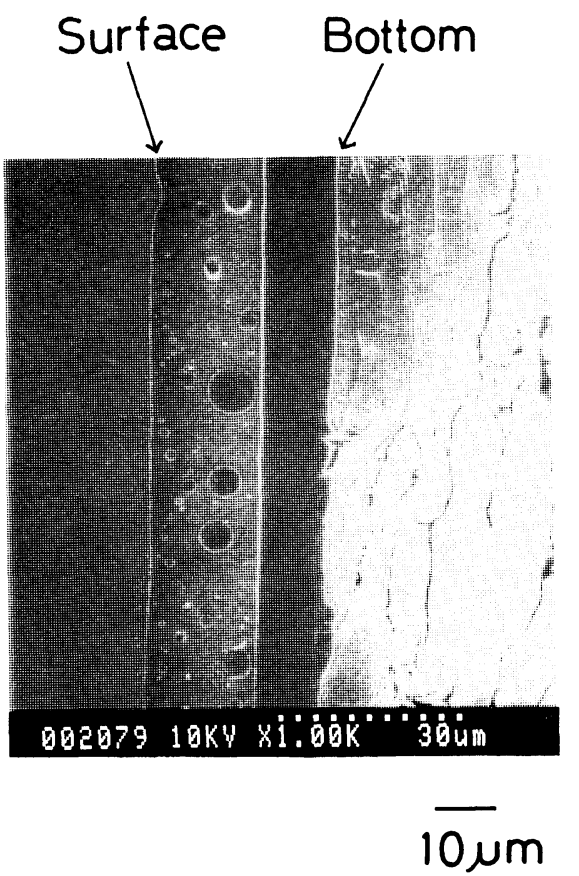

Figure 9. SEM photograph of sectional layer for P(2EHA-AAVAc)/P(VDF-HFA) (30/70) blend annealed at $160^{\circ} \mathrm{C}$ for 2 days. 
temperature. We examined the morphology of sectional layer for the blends with elapsed time (a few years). However, the domain morphology of the blend did not change with time. The tackiness of surface and bottom did not also change with elapsed time. We considered that the domain morphology changed only above the melting temperature $T_{\mathrm{m}}$.

\section{CONCLUSIONS}

The gradient structure was found for the $\mathrm{P}(2 \mathrm{EHA}$ AA-VAc)/P(VDF-HFA) (30/70) blend thin film. The elipsoidal domain corresponded to $\mathrm{P}(2 \mathrm{EHA}-\mathrm{AA}-\mathrm{VAc})$ particle was observed and its size increased from surface to bottom. The P(2EHA-AA-VAc) layer having $\sim 10 \mu \mathrm{m}$ thickness was formed at bottom side. The characteristic gradient domains were reduced by adding the micrograin silica (R972, MOX170) into P(2EHA-AA-VAc)/P(VDFHFA) $(30 / 70)$ blend. The pressure sensitive adhesive properties $\left(180^{\circ}\right.$ peel adhesion and probe tack) were also changed by adding the micrograin silica. By annealing, the elipsoidal domain of P(2EHA-AA-VAc) component changed to spherical domain by annealing at $160^{\circ} \mathrm{C}$ for 2 days.

Acknowledgments. The authors express their thanks to Dr. K. Maeda of Central Glass Co., Ltd. for supplying P(VDF-HFA), Mr. Y. Fujita of Hitachi Kasei Polymer Co., Ltd. for SEM observation of surface and bottom and Dr. Y. Kitazaki of Nichiban Co., Ltd. for probe tack. The author, Y. Kano is a research fellow of the
Japan Society for the Promotion of Science belonged to the Ministry of Education, Science, and Culture of Japan.

\section{REFERENCES}

1. K. Shioda, Kagaku, 46, 131 (1991).

2. Y. Agari, M. Shimada, A. Ueda, and S. Nagai, Macromol. Chem. Phys., 197, 2017 (1996).

3. T. Okazaki, M. Furukawa, and T. Yokoyama, Polym. Prepr. Jpn., 45, 657 (1996).

4. Y. Kano, K. Ishikura, S. Kawahara, and S. Akiyama, Polym. J., 24, 135 (1992)

5. Y. Kano, S. Akiyama, and T. Kasemura, J. Appl. Polym. Sci., 50, 1619 (1993).

6. Y. Kano, S. Akiyama, T. Kasemura, and S. Kobayashi, Polym. J., 27, 339 (1995).

7. Y. Kano, S. Akiyama, H. Sano, and H. Yui, J. Electron Microsc., 44, 344 (1995).

8. Y. Kano, S. Akiyama, S. Kobayashi, and T. Yokoyama, Nippon Setchaku Gakkaishi, 32, 1 (1996).

9. Y. Kano, S. Akiyama, and S. Kobayashi, J. Adhesion, 55, 261 (1996).

10. Y. Kano, S. Akiyama, H. Sano, and H. Yui, Nippon Setchaku Gakkaishi, 32, 164 (1996).

11. T. Inoue, T. Ougizawa, O. Yasuda, and K. Miyasaka, Macromolecules, 18, 57 (1985).

12. M. Sato, S. Akiyama, and S. Honda, Kobunshi Ronbunshu, 47, 287 (1990).

13. Y. H. Kim, S. Akiyama, and A. Matsuda, Kobunshi Ronbunshu, 53, 169 (1996).

14. Y. Kano, S. Akiyama, and T. Kasemura, Int. J. Adhesion and Adhesives, 15, 219 (1995).

15. S. Akiyama and Y. Kano, "Polymeric Material Encyclopedia," Vol. 4, J. C. Salamone, Ed., CRC Press, Boca Raton, Florida, 1996, F-G, P2484. 